\title{
ASSESSMENT OF THE EFFECTS OF SUGARCANE STRAW ADDITION TO THE FLOCCULATION/COAGULATION PROCESS ON VINASSE CONCENTRATION
}

\author{
Pietro SICA*, Renan CARVALHO, Hélder BELTRAME, Antonio Sampaio BAPTISTA \\ University of Sao Paulo, Piracicaba, Sao Paulo, Brazil
}

\begin{abstract}
Vinasse is the main by-product of ethanol production. In 2005, its application was regulated in the state of Sao Paulo, so if it is to be applied to the fields, its volume must meet the established concentration regulations. Straw contains one-third of sugarcane calorific value and can be used for cogeneration. For these purposes, the project objective was to assess the effects of straw on the concentration of vinasse solids through physical and chemical processes, so its concentrated form could be used as biomass for cogeneration. For that, different concentrations of straw, ferric sulphate, and ferric chloride were used. Turbidity reduction was the parameter analysed. Both reagents were effective in reducing the turbidity. The $200 \mathrm{ppm}$ of ferric chloride and $0.25 \%$ straw content reduced the turbidity by $55.02 \%$ and $400 \mathrm{ppm}$ of ferric sulphate and $0.25 \%$ of straw reduced it by $57.96 \%$. The addition of straw showed no significant effect in terms of the turbidity reduction, however, both best treatments had $0.25 \%$ straw content addition in it. Straw can be used to concentrate vinasse, contributing to the efficiency of the process and increasing the energy potential of the concentrated solids.
\end{abstract}

Keywords: vinasse concentration; biofertilizer; physical and chemical treatments; water recovery; turbidity reduction

Brazil is the world's largest producer of sugarcane ethanol, producing approx. 33 billion litres of ethanol in the 2018/2019 harvest season (Brazilian Sugarcane Industry Association, 2019). Ethanol consists of the same chemical compound, regardless of whether it is produced from starch (e.g. corn), or fermentable sugars (sugarcane) (Božiková and Hlaváč, 2013). Sugarcane ethanol is considered more renewable, cleaner and sustainable than the corn ethanol. By-products generated in sugarcane ethanol production process include vinasse, which is the main liquid by-product of sugar-ethanol industry (Moraes et al., 2015); it is composed of $93 \%$ water and $7 \%$ minerals (mainly potassium) and organic matter (Laime et al., 2011; Ferreira et al., 2011) and is 100 times more pollutant than domestic sewage (Freire and Cortez, 2000). For each litre of ethanol produced, 10-15 litres of vinasse are generated (Silva et al., 2013).

The main application of vinasse is as biofertilizer for its high potassium content. However, besides the organic content, it has high pollutant capacity; when applied to the soil, high concentrations of $\mathrm{K}^{+}$ions can form chemical complexes, promoting the leaching of anions, such as nitrate, and polluting the groundwaters (Rodella et al., 1983). The state of Sao Paulo produced 16 billion litres of ethanol in the 2018/2019 harvest season (Brazilian Sugarcane Industry Association, 2019) and generated approx. 160-240 billion litres of vinasse for this same period. The Guarani Aquifer System (SAG) is considered one of the most important in the world and $80 \%$ of its total exploited yield for drinking and industrial utilization is in the state of Sao Paulo (Foster et al., 2009). Hirata et al. (1991) considered sugar and ethanol plants to be part of the group classified as high potential contaminant load to the state of Sao Paulo groundwaters. For these reasons, in 2005, the Sao Paulo's State Sanitation Company (CETESB) established the P4.231 technical standard regulating the vinasse application; it disallows the $\mathrm{K}^{+}$concentration in the soil to exceed $5 \%$ of the cation exchange capacity (CEC) (State of Sao Paulo, 2005). One of the consequences of this regulation is that now the vinasse must be applied to larger areas (Silva et al., 2013), increasing the application and handling costs. Increased machinery traffic over fields causes soils compaction, damaging the soil structure and degrading the soil functions (Galambošová et al., 2020). One of the solutions for this issue is to concentrate the vinasse solids in the industry and take smaller volumes of it to the field. Furthermore, the combustion of vinasse solids or its incineration for the recovery of potassium salts and energy are other alternatives (Freire and Cortez, 2000).

On September 19, 2002, the State of Sao Paulo approved the Act no. 11.241 (State of Sao Paulo, 2002), gradually banning the burning of sugarcane before harvesting, by 2021 (Aguiar et al., 2011). The manual harvesting of sugarcane has been and is gradually being replaced by mechanized harvesting with efficiency of 10-20 tons of dry leaves per hectare in the top of the soil under the system known as green cane management. Sugarcane straw represents approx. one-third of the total primary calorific value of sugarcane in the field (Leal et al., 2013). However, the greatest agronomic and environmental benefits of leaving the straw on the field result from leaving at least

Contact address: Pietro Sica, University of Sao Paulo, Food and Nutrition, College of Agriculture "Luiz de Queiroz", Department of Agri-food Industry, 11 Padua Dias Avenue, 13418-900, Piracicaba, Sao Paulo, Brazil, e-mail: pietros0394@gmail.com 
7 tons of sugarcane straw per hectare. Consequently, 3-13 tons of straw per hectare can be harvested by power generation purposes (Carvalho et al., 2017). To enhance the sugar-energy sector sustainability, it is necessary to optimize the utilization of sugarcane energy content. In the field, one ton of sugarcane has $7,188 \times 10^{3} \mathrm{~kJ}$, which is more than one barrel of crude oil has $\left(5,799 \times 10^{3} \mathrm{~kJ}\right)$. This one ton of sugarcane provides $276 \mathrm{~kg}$ of bagasse with $50 \%$ moisture content that has $2,502 \times 10^{3} \mathrm{~kJ}, 165 \mathrm{~kg}$ of straw with $15 \%$ moisture content that has $2,142 \times 10^{3} \mathrm{~kJ}$, and $153 \mathrm{~kg}$ of sugar $\left(2,543 \times 10^{3} \mathrm{~kJ}\right)$. Part of the sugar calorific value goes to the sugar production, another part to the ethanol production, and the rest "disappears" in the vinasse (Oliverio, 2016).

This project aims to assess the efficiency of flocculation/ coagulation and centrifugation processes to concentrate the vinasse solids together with sugarcane straw in order to increase the calorific power of the concentrated solids, so that they can be used for cogeneration. Moreover, the vinasse water can be recovered and reused for the industrial purposes. For that, different concentrations of ferric chloride and ferric sulphate were added to the vinasse samples (with and without sugarcane straw), which were subsequently centrifuged. The vinasse turbidity was the main parameter used to compare the samples.

\section{Material and methods}

The straw was collected in Bariri, state of São Paulo, using rake and sacks. Subsequently, it was transported to the Sugar and Alcohol Laboratory of the College of Agriculture "Luiz de Queiroz", University of Sao Paulo campus in Piracicaba (ESALQ/USP). The straw was shredded and sieved to $0.3 \mathrm{~mm}$ particle size.

Vinasse for analysis was obtained by fermentation in 7 I reactors. Sugarcane juice used for fermentation $\left(18^{\circ} \mathrm{Bx}\right)$ was obtained from the dilution of stored syrup $\left(55^{\circ} \mathrm{Bx}\right)$ at the Sugar and Alcohol Laboratory of ESALQ/USP.

Flocculating agents used were ferric sulphate and ferric chloride.

\section{Turbidity}

Turbidity is a physical property of fluids that translates into reduced transparency due to the presence of suspended materials that interfere with the passage of light through the fluid and can be measured based on the difficulty of the light to pass through the liquid (USGS, 2019). The turbidity was used to access the efficiency of each treatment in terms of reducing the solids content of the vinasse and was determined by using a $2100 \mathrm{Q}$ portable turbidimeter by Hach Company. This equipment has two-detector optical system that compensates for colour in the sample, light fluctuation, and stray light. It is calibrated with a standard curve with 6 different turbidity values ranging from 0 to 1000 NTU (nephelometric turbidity units). These suspended materials can be decanted or removed from the liquid with flocculation, coagulation and centrifugation. For this reason, the turbidity was used as the main parameter to determine the efficiency of the treatments in terms of concentrating the suspended vinasse solids. The turbidity reduction was calculated in percentage as follows: turbidity reduction $=\frac{(\text { initial turbidity }- \text { final turbidity }) \times 100}{\text { initial turbidity }}$

\section{Experimental design}

Three different concentrations of straw were used: $0.0 \%$ (S0\%), $0.1 \%$ (S0.1\%), and $0.25 \%$ (S0.25\%). For all three straw concentrations, 0 ppm, 50 ppm, 100 ppm, and 200 ppm of ferric chloride (FC) and ferric sulphate (FS) were used. For the $0.25 \%$ concentration of sugarcane straw, the concentrations of 300 ppm, 400 ppm, and 500 ppm were also used. In total, the following 27 treatments were performed: 1) SO - no reagent; 2) S1 - no reagent; 3) S2 - no reagent; 4) SO - FS50; 5) S0 - FS100; 6) SO - FS200; 7) S0 - F(50; 8) S0 - FC100; 9) S0 - F(200; 10) S1 - FS50; 11) S1 - FS100; 12) S1 - FS200; 13) S1 - FC50; 14) S1 - FC100; 15) S1 - FC200; 16) S2 - FS50; 17) S2 - FS100; 18) S2 - FS200; 19) S2 - FS300; 20) S2 - FS400; 21) S2 - FS500; 22) S2 - F(50; 23) S2 - F(100; 24) S2 - F(200; 25) S2 - FC300; 26) S2 - FC400; 27) S2 - FC500.

Each treatment was replicated 4 times. Vinasse was transferred to $50 \mathrm{ml}$ Falcon tubes and mixed with the straw after mixing with the reagent. Then, it was centrifuged at $4,000 \mathrm{rpm}$ for $5 \mathrm{~min}$. The supernatant was collected, the turbidity after treatment was measured, and the turbidity reduction for each experimental sample was calculated according to Eq. 1. The vinasse used was homogenized and the measured initial turbidity was 936 NTU.

\section{Statistical analysis}

The data obtained were analysed using the software R. First, ANOVA. Utilizing the Tukey HSD test (5\%), the effects of ferric sulphate and ferric chloride on the turbidity reduction of vinasse were assessed. Subsequently, the effects of adding straw in different concentrations were evaluated by running ANOVA and Tukey HSD test (5\%). The effects of different straw and reagent concentrations were also assessed by using ANOVA and Tukey HSD test (5\%).

\section{Results and discussion}

The treatments without straw addition showed an average turbidity reduction of $47.15 \%$ and no significant differences in contrast to the treatments with $0.1 \%(p=0.214)$ and $0.25 \%$ of straw ( $p=0.695$ ). The treatments with $0.1 \%$ straw content showed the lowest turbidity reduction - by $44.87 \%$ - which is significantly different from the treatments with $0.25 \%$ straw content $-48.25 \%$ ( $p=0.037$ ) (Fig. 1). The straw addition had no influence on the turbidity reduction; however, the process can be influenced by different concentrations of straw. Although the data is not presented in this manuscript, treatments with $0.50 \%$ and $1.00 \%$ straw contents were also performed in a preliminary study. Such larger straw contents made the centrifugation process difficult, as it was unable to remain at the base of the tubes, rising and bringing the vinasse solids after centrifugation, reducing the final turbidity by less than $28 \%$.

The addition of flocculants showed an effect on the vinasse turbidity reduction. The control treatments (C) with no reagents added reduced the turbidity by $40.14 \%$ and were significantly different in comparison to the 


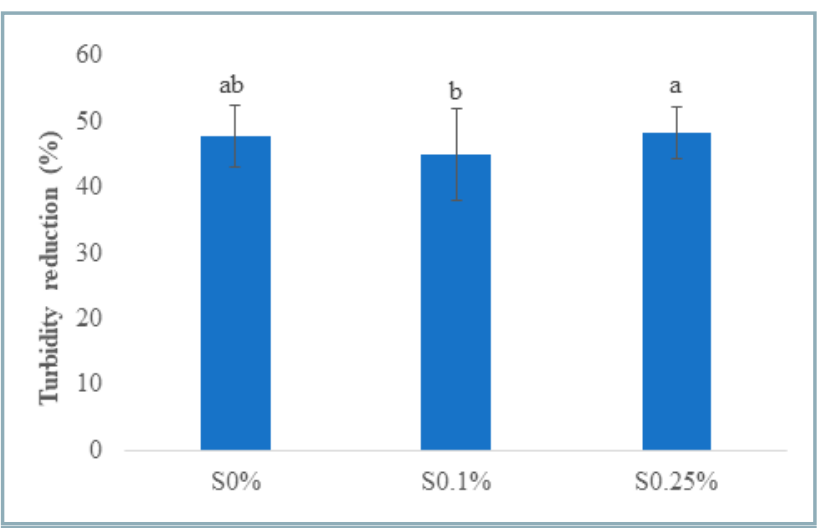

Fig. 1 Dependency of turbidity reduction on different straw content addition

treatments with ferric chloride, $49.57 \%(p=0.000)$, and with ferric sulphate, $50.97 \%(p=0.000)$. There was no significant difference between the treatments with ferric chloride and ferric sulphate ( $p=0.222$ ) (Fig. 2).

Different straw and flocculant concentrations also influenced the vinasse turbidity reduction. Considering the sole ferric sulphate application, the turbidity reduction significantly increased from $42.55 \%(0 \mathrm{ppm})$ to $52.83 \%$ (200 ppm) (Table 1).

When $0.1 \%$ straw content was added to the process, the treatment with no reagent was also the one with lower value, $33.95 \%$, and the turbidity reduction increased significantly with the addition of $50 \mathrm{ppm}(47.30 \%)$ of ferric sulphate. The highest significant reduction was observed in treatments with addition of $100 \mathrm{ppm}(51.12 \%)$ and $200 \mathrm{ppm}$ (50.24\%) of ferric sulphate (Table 1 ).

All in all, the treatments with $0.25 \%$ straw content and higher amounts of ferric sulphate showed high turbidity reduction. For those treatments, the increasing of the reagent concentration from $0 \mathrm{ppm}$ to $400 \mathrm{ppm}$ also increased the turbidity reduction - from $43.94 \%$ to $57.96 \%$. However, when increasing from $400 \mathrm{ppm}$ to $500 \mathrm{ppm}$, although there was no significant difference, the turbidity reduction decreased to $55.85 \%$, since addition of the reagent achieved a saturation point, at which adding more reagent does not affect the turbidity reduction positively. The treatment with addition of $400 \mathrm{ppm}$ and $0.25 \%$ straw content showed the highest turbidity reduction and had significant difference

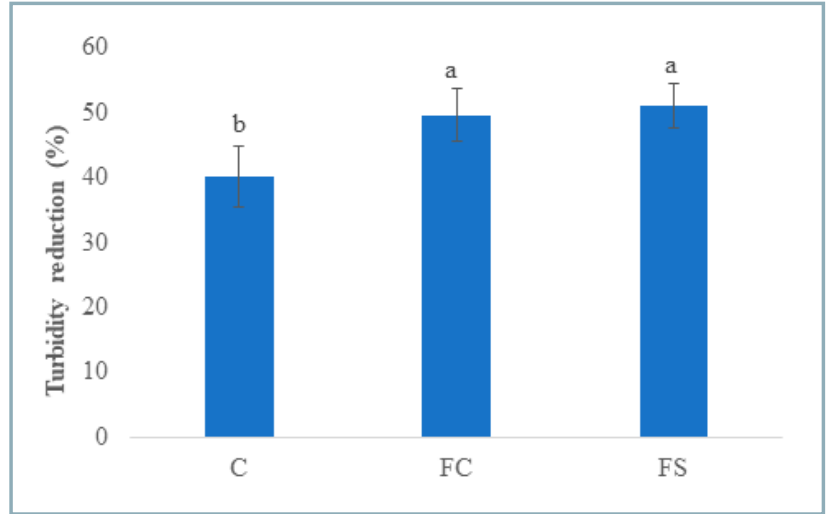

Fig. 2 Dependency of turbidity reduction on different reagents

in contrast to the treatment with addition of $500 \mathrm{ppm}$ and $0.25 \%$ of straw. The latter showed no significant difference in comparison to the treatments with addition of $200 \mathrm{ppm}$ and no straw; $0.1 \%$ straw content and 100 ppm and 200 ppm; and $0.25 \%$ straw content and 300 ppm and 200 ppm (Table 1).

Different concentrations of ferric chloride also affected the turbidity reduction. Without straw addition, the turbidity reduction increased as the amount of applied ferric chloride increased: from $42.55 \%$ at 0 ppm to $52.94 \%$ at $200 \mathrm{ppm}$. The treatment with $200 \mathrm{ppm}$ showed no significant difference in comparison to the treatment with $100 \mathrm{ppm}$ (50.27\%) (Table 2).

The turbidity reduction also increased, as the reagent concentration increased with $0.1 \%$ straw addition: from $33.95 \%$ without any reagent application to $51.98 \%$ with application of $200 \mathrm{ppm}$ of ferric chloride. The treatment with 200 ppm was significantly different in contrast to the others. There was no significant difference between the treatments with 50 ppm and 100 ppm, 43.32\% and $47.09 \%$, respectively.

Considering the treatments with $0.25 \%$ straw, the turbidity reduction increased from $43.94 \%$ to $55.02 \%$ as the ferric chloride concentration increased from $0 \mathrm{ppm}$ to $200 \mathrm{ppm}$. The treatment with $200 \mathrm{ppm}$ had no significant difference when compared to the treatment with $300 \mathrm{ppm}$ (52.19\%) and $400 \mathrm{ppm}$ (53.63\%). The treatment with 500 ppm decreased the turbidity reduction to $49.36 \%$, since addition of the reagent achieved a saturation point, at which

Table 1 Turbidity reduction showed by treatments with different concentrations of ferric sulphate and straw

\begin{tabular}{|c|c|c|c|c|c|c|}
\hline \multirow{3}{*}{$\begin{array}{l}\text { Ferric sulphate } \\
0 \text { ppm }\end{array}$} & \multicolumn{2}{|c|}{ S 0\% } & \multicolumn{2}{|c|}{ S $0.1 \%$} & \multicolumn{2}{|c|}{ S $0.25 \%$} \\
\hline & \multicolumn{6}{|c|}{ turbidity reduction (\%) } \\
\hline & $42.55 \pm 0.72$ & $f$ & $33.95 \pm 1.75$ & $g$ & $43.94 \pm 1.58$ & def \\
\hline 50 ppm & $46.85 \pm 0.32$ & de & $47.30 \pm 1.21$ & de & $47.36 \pm 1.90$ & de \\
\hline 100 ppm & $49.65 \pm 1.15$ & de & $51.12 \pm 0.52$ & bcd & $48.02 \pm 0.97$ & de \\
\hline 200 ppm & $52.83 \pm 0.47$ & bc & $50.24 \pm 0.31$ & bcde & $51.47 \pm 0.73$ & $\mathrm{bc}$ \\
\hline 300 ppm & \multicolumn{2}{|c|}{-} & \multicolumn{2}{|c|}{-} & $52.99 \pm 0.88$ & $\mathrm{bc}$ \\
\hline 400 ppm & \multicolumn{2}{|c|}{-} & \multicolumn{2}{|c|}{-} & $57.96 \pm 0.49$ & $\mathrm{a}$ \\
\hline 500 ppm & \multicolumn{2}{|c|}{-} & \multicolumn{2}{|c|}{-} & $55.85 \pm 0.47$ & $a b$ \\
\hline
\end{tabular}

Different letters indicate that there was a significant difference between treatments at a $5 \%$ significance level (Tukey test) 
Table 2 Turbidity reduction of treatments with different concentrations of ferric chloride and straw

\begin{tabular}{|c|c|c|c|c|c|c|}
\hline \multirow{3}{*}{$\begin{array}{l}\text { Ferric chloride } \\
0 \text { ppm }\end{array}$} & \multicolumn{2}{|c|}{ S 0\% } & \multicolumn{2}{|c|}{ S $0.1 \%$} & \multicolumn{2}{|c|}{$\mathrm{S} 0.25 \%$} \\
\hline & \multicolumn{6}{|c|}{ turbidity reduction (\%) } \\
\hline & $42.55 \pm 0.72$ & e & $33.95 \pm 1.75$ & $f$ & $43.94 \pm 1.58$ & e \\
\hline 50 ppm & $42.84 \pm 0.93$ & e & $43.32 \pm 1.47$ & e & $45.51 \pm 1.60$ & e \\
\hline 100 ppm & $50.27 \pm 0.76$ & $\mathrm{~cd}$ & $47.09 \pm 1.51$ & de & $50.72 \pm 0.90$ & $\mathrm{bc}$ \\
\hline 200 ppm & $52.94 \pm 0.54$ & $a b c$ & $51.98 \pm 0.76$ & $a b c$ & $55.02 \pm 1.31$ & $\mathrm{a}$ \\
\hline 300 ppm & \multicolumn{2}{|c|}{-} & \multicolumn{2}{|c|}{-} & $52.19 \pm 0.39$ & $a b c$ \\
\hline 400 ppm & \multicolumn{2}{|c|}{-} & \multicolumn{2}{|c|}{-} & $53.63 \pm 0.34$ & $\mathrm{ab}$ \\
\hline 500 ppm & \multicolumn{2}{|c|}{-} & \multicolumn{2}{|c|}{-} & $49.36 \pm 1.15$ & $\mathrm{~cd}$ \\
\hline
\end{tabular}

Different letters indicate that there was a significant difference among the treatments at a $5 \%$ significance level (Tukey test)

adding more reagent does not affect the turbidity reduction positively.

Based on the results obtained in this study, it is possible to affirm that the ferric chloride and the ferric sulphate can increase the vinasse solids concentration and its water recovery efficiency. Following the methods established by Souza et al. (2013b), Souza et al. (2013a) used a commercial vegetable tannin ( TanFloc $^{\oplus}$ ) to clarify that by adding $2.5 \%$ of tannin to the vinasse, the turbidity fell by $70 \%$. Similarly, Souza et al. (2013b) manage to reduce it by more than $90 \%$ in a similar manner. However, Souza et al. (2013b) highlighted that the simple process of coagulation/flocculation without adding toxic components was able to reduce the vinasse turbidity and concentrate its solids. In addition to this, these studies used photocatalytic processes to degrade the remaining vinasse organic content. Ferric chloride and ferric sulphate consist of iron and chlorine, and iron and sulphate, respectively. Taking into account that the concentrated solids contain minerals that are going to be applied to the field, those components added to the vinasse are also going to be applied to the field. Sulphate is a macronutrient, and iron and chlorine are micronutrients essential for the plant development, therefore, utilization of these reagents is not going to be toxic to the sugarcane in the field and will not pose the same toxicity issue of $\operatorname{TanFloc}^{\circledR}$ highlighted by Souza et al. (2013b).

Flocculation and coagulation processes were able to reduce the vinasse turbidity and concentrate its solids, however, the supernatant still retains almost half of it. In order to remove these solids completely and recover the water, a process or sequence of processes would be required after this step. Souza et al. (2013a; 2013b) observed that a photocatalytic degradation reduced the organic load of the vinasse by almost $80 \%$. Sica et al. (2017) filtered the supernatant in a sand filter, reducing the turbidity and total solids by more than $90 \%$, reaching final $\mathrm{pH}$ of approx. 7.0, thus obtaining treated clear water that could be reused in industrial processes.

\section{Conclusion}

The flocculation/coagulation process to concentrate the vinasse solids is more efficient with application of ferric chloride and ferric sulphate. The best results were obtained with application of $200 \mathrm{ppm}$ ferric chloride and $0.25 \%$ of straw, reducing the turbidity by $55.02 \%$. Considering the ferric sulphate application, the best results were achieved at $400 \mathrm{ppm}$ and $0.25 \%$ of straw, reducing the turbidity by $57.96 \%$.

In terms of comparison of treatments with straw addition, the straw content of $0.25 \%$ showed no significant difference in contrast to the samples without straw. However, the treatments with ferric sulphate showed higher turbidity reduction with application of $0.25 \%$ of straw. Furthermore, addition of $0.1 \%$ and $0.25 \%$ of straw showed no negative impacts on this process and can increase the calorific power of the concentrated vinasse solids.

Although the proposed treatments were able to concentrate the vinasse solids, the flocculation/coagulation process alone was not enough for these purposes. However, it can be considered as a suitable pre-treatment. Therefore, further studies are necessary to assess different processes that can be added after this pre-treatment and make the vinasse concentration more efficient.

\section{References}

AGUIAR, D. A. - RUDORFF, B. F. T. - SILVA, W. F. - ADAMI, M. - MELLO, M. P. 2011. Remote sensing images in support of environmental protocol: monitoring the sugarcane harvest in Sao Paulo State, Brazil. In Remote Sensing, vol. 3, no. 12, pp. 2682-2703.

BOŽIKOVÁ, M. - HLAVÁČ, P. 2013. Thermal conductivity and thermal diffusivity of biodiesel and bioethanol samples. In Acta Technologica Agriculturae, vol. 16, no. 4, pp. 90-94.

CARVALHO, J. - NOGUEIROL, R. - MENANDRO, L. - BORDONAL, R. - BORGES, C. - CANTARELLA, H. - FRANCO, H. 2017. Agronomic and environmental implications of sugarcane straw removal: a major review. In Global Change Biology - Bioenergy, vol. 9, no. 7, pp. 1181-1195.

FERREIRA, L. F. R. - AGUIAR, M. M. - MESSIAS, T. G. - POMPEU, G. B. - LOPEZ, A. M. Q. - SILVA, D. P. - MONTEIRO, R. T. 2011. Evaluation of sugar-cane vinasse treated with Pleurotus sajor-caju utilizing aquatic organisms as toxicological indicators. In Ecotoxicology and Environmental Safety, vol. 74, no. 1, pp. 132-137.

FOSTER, S. - HIRATA, R. - VIDAL, A. - SCHMIDT, G. - GARDUÑO, H. 2009. The Guarani Aquifer initiative - towards realistic groundwater management in a transboundary context. In Groundwater Management Advisory Team (GW-MATE) 2009. Washington: World Bank. Available at: https://www.un-igrac.org/sites/default/files/ resources/files/GWMATE\%20case\%20profile\%20-\%20Guarani.pdf. Accessed on December 03, 2019. 
FREIRE, W. J. - CORTEZ, L. A. B. 2000. Vinasse from sugarcane (in Portuguese). Guaíba (Brazil): Agropecuária, 203 pp.

GALAMBOŠOVÁ, J. - MACÁK, M. - RATAJ, V. - BARÁT, M. - MISIEWICZ, P. 2020. Determining trafficked areas using soil electrical conductivity - a pilot study. In Acta Technologica Agriculturae, vol. 23, no. 1, pp. 1-6.

HIRATA, R. C. A - BASTOS, C. R. A. - ROCHA, G. A. - GOMES, D. C. IRITANI, M. A. 1991. Ground water pollution risk and vulnerability map of the state of Sao Paulo, Brazil. In Water Science and Technology, vol. 24, no. 11, pp. 159-169.

LAIME, E. M. O. - FERNANDES, P. D. - OLIVEIRA, D. C. S. - FREIRE, E. A. 2011. Technological possibilities for the destination of vinasse: a review (in Portuguese). In Revista Trópica: Ciências Agrárias e Biológicas, vol. 5, no. 3, pp. 16-29.

LEAL, M. R. L. V. - GALDOS, M. V. - SCARPARE, F. V. - SEABRA, J. E. A. - WALTER, A. - OLIVEIRA, C. O. 2013. Sugarcane straw availability, quality, recovery and energy use: a literature review. In Biomass and Bioenergy, vol. 53, no. 6, pp. 11-19.

MORAES, B. S. - ZAIAT, M. - BONOMI, A. 2015. Anaerobic digestion of vinasse from sugarcane ethanol production in Brazil: challenges and perspectives. In Renewable and Sustainable Energy Reviews, vol. 44, no. 4, pp. 888-903.

OLIVERIO, J. L. 2016. The Dedini and the private effort during 40 years of Pro-Alcohol, or... from the sugar mill to the sustainable plant (in Portuguese). In FAPESP (Sao Paulo Research Foundation), Available at: http://www.fapesp.br/eventos/2016/11/proalcool/ Dedini.pdf. Accessed on February 28, 2020.

RODELLA, A. A. - ZAMBELLO, E. - FRANCISCO, J. O. 1983. Effects of vinasse added to soil on $\mathrm{pH}$ and exchangeable aluminum content In Congress of the International Society of Sugar Cane Technologists 1983. Havana: Jose Marti Publishing House, pp. 237-247.

SICA, P. - BAPTISTA, A. S. - DAS, K. C. - PIOTROVSKI, J. 2017. Development of physical and chemical processes to increase the efficiency of concentration of vinasse's solids. In Journal of Environmental Sciences and Engineering A, vol. 6, no. 2, pp. 90-97. SILVA, A. - ROSSETTO, R. - BONNECINE, J. - PIEMONTE, M. MURAOKA, T. 2013. Net and potential nitrogen mineralization in soil with sugarcane vinasse. In Sugar Technology, vol. 15, no. 2, pp. 159-164.
SOUZA, R. P. - FERRARI-LIMA, A. M. - SEIXAS, F. L. - BATISTELA, V. R. - FAVARO, S. L. - HIOKA, N. - FERNANDES-MACHADO, N. R. C. 2013a. Evaluation of $\mathrm{ZnO}$ catalyst supported on zeolite $\mathrm{NaA}$ in the photocatalytic degradation of vinasse pretreated by coagulation/ flocculation. In Chemical Engineering Transactions, vol. 32, pp. 823-828.

SOUZA, R. P. - GIRARDI, F. - SANTANA, V. S. - FERNANDESMACHADO, N. R. C. - GIMENES, L. M. 2013b. Vinasse treatment using vegetable-tanning coagulant and photocatalysis. In Acta Scientiarum - Technology, vol. 35, no. 1, pp. 89-95.

State of Sao Paulo. Law 11.241 Provides for the gradual elimination of the burning of sugarcane straw and gives related measures (in Portuguese). Available at: https://www.al.sp.gov.br/repositorio/ legislacao/lei/2002/lei-11241-19.09.2002.html. Accessed on December 3, 2019.

State of Sao Paulo's Technical Standard P4.231/2005. Sillage Criteria and procedures for agricultural application.

UNICA (BRAZILIAN SUGARCANE INDUSTRY ASSOCIATION). 2019. Sugarcane, ethanol and sugar production - 2018/2019 harvest season. Available at: http://www.unicadata. com.br/historico-de-producao-e-moagem.php?idMn= 32\&tipoHistorico $=4 \&$ acao $=$ visualizar\&idTabela $=2336 \&$ safra $=$ 2018\%2F2019\&estado=RS\%2CSC\%2CPR\%2CSP\%2CRJ\%2CMG\% 2CES \% 2CM S \% 2CM T \% 2C G O 2 CDF \% 2CB A \% 2CSE $\% 2$ CAL $\% 2$ CPE $\% 2$ CPB $\% 2$ CRN \% 2CCE \% 2CPI\% 2 CMA \% 2CTO\%2CPA\%2CAP\%2CRO\%2CAM\%2CAC\%2CRR. Accessed on December 03, 2019.

USGS (United States Geological Survey). 2019. Water and Turbidity. Available at: https://www.usgs.gov/special-topic/water-scienceschool/science/turbidity-and-water?qt-science center objects= 0\#qt-science center objects. Accessed on February 28, 2020. 